\title{
Sensitivity analysis of fire resistance of a composite floor slab
}

\author{
Joanna Kaliszuk*, and Elżbieta Grochowska \\ University of Zielona Góra, Faculty of Civil Engineering, Architecture and Environmental \\ Engineering, ul. Licealna 9, 65-417 Zielona Góra, Poland
}

\begin{abstract}
The paper presents a sensitivity analysis of design bending resistance of a composite slab rib in a fire situation to a change of the value of basic variables. The analysis was carried out for a composite slab being an element of a supporting structure of a reinforced floor referred to in [1, 2]. The calculations were made for a simple calculation model and the standard temperature-time curve according to $[6,7]$. The set of basic variables was limited to $\mathbf{X}_{\mathbf{1}}=\left\{(y, z), h_{1}, f_{y, a}, f_{y, s}, f_{c}\right\}$.
\end{abstract}

\section{Introduction}

According to the Regulation of the Minister of Infrastructure [3], every building should meet relevant requirements concerning its fire resistance. Such requirements are determined by defining for a particular building a human risk category (ZL) and the corresponding fire resistance category (OP). For each OP category of a building there is a set of requirements for fire resistance classes $(\mathrm{OO})$ defined for particular elements of a building, such as: primary supporting structure, roof structure, floor, external wall, internal wall, roofing. Fire resistance is expressed by the minimum time $t_{f i}$, calculated from the flashover, after which a particular element of a building meets the ultimate limit states referred to in $[4,7]$, namely: fire ultimate limit state $R$, fire insulation limit state $I$, fire integrity limit state $E$.

The paper analyzes fire resistance of a reinforced wood floor, being an element of the renovated building referred to in [1]. Owing to the expected method of use, the building in which the analyzed floor is located should meet the requirements defined in fire resistance class B, see [1]. In a building rated as class B, the floor should be provided with the fire resistance rated as REI 60 meaning, that after 60 minutes upon the flashover, the floor must comply with the requirements of the limit states, $R, E, I$ respectively, see $[3,4]$.

The analysis presented in the paper is limited only to fire resistance $R$ of a separated element of the floor reinforcement, which in this case is a composite steel-concrete slab. The authors assumed the slab fire resistance $R$ as the design sagging moment resistance at time $t=60$ minutes $M_{f i, t, R d}$, determined according to [7] for its rib. The change of the moment value $M_{f i, t, R d}$ corresponding to the values of basic variables of the assumed calculation model was investigated.

\footnotetext{
* Corresponding author: j.kaliszuk@ib.uz.zgora.pl
} 


\section{Description of the analyzed element}

The elements of the analyzed composite steel-concrete slab are the following [5]:

- Cofrastra 40 profiled steel sheet with the thickness of $t=0,75 \mathrm{~mm}$, made of S350 GD steel with the yield strength of $f_{y, a}=350 \mathrm{MPa}$,

- $\mathrm{C} 25 / 30$ concrete with the design strength of $f_{c}=25 \mathrm{MPa}$,

- additional reinforcement bar with the diameter of $\phi=6 \mathrm{~mm}$, made of A-III N/RB 500W reinforced steel, the yield strength of $f_{y, s}=500 \mathrm{MPa}$, placed on the steel fold in order to ensure the fire resistance assumed for the floor.

The cross-section diagram of the analyzed composite slab is presented in Fig.1

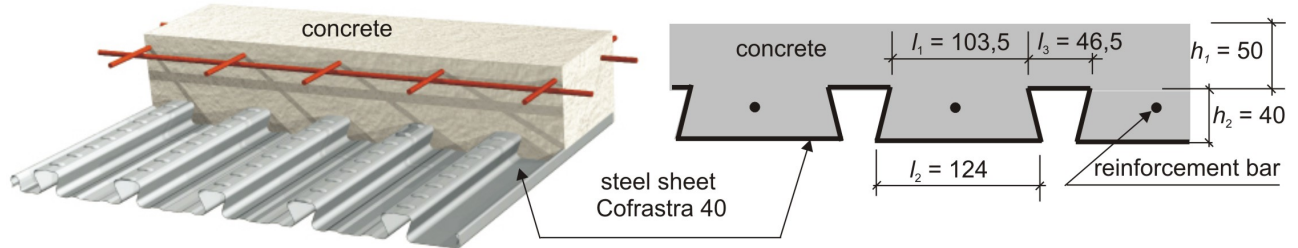

Fig.1. The cross-section of the analyzed composite steel-concrete slab Cofrastra 40

\section{Calculation model}

The fire resistance of the slab was referred to the design value of the sagging moment resistance in the fire situation at time $t=60$ minutes $M_{f i, t, R d}$, determined according to [7] for its rib. The cross-section of the analyzed rib is presented in Fig. 2.

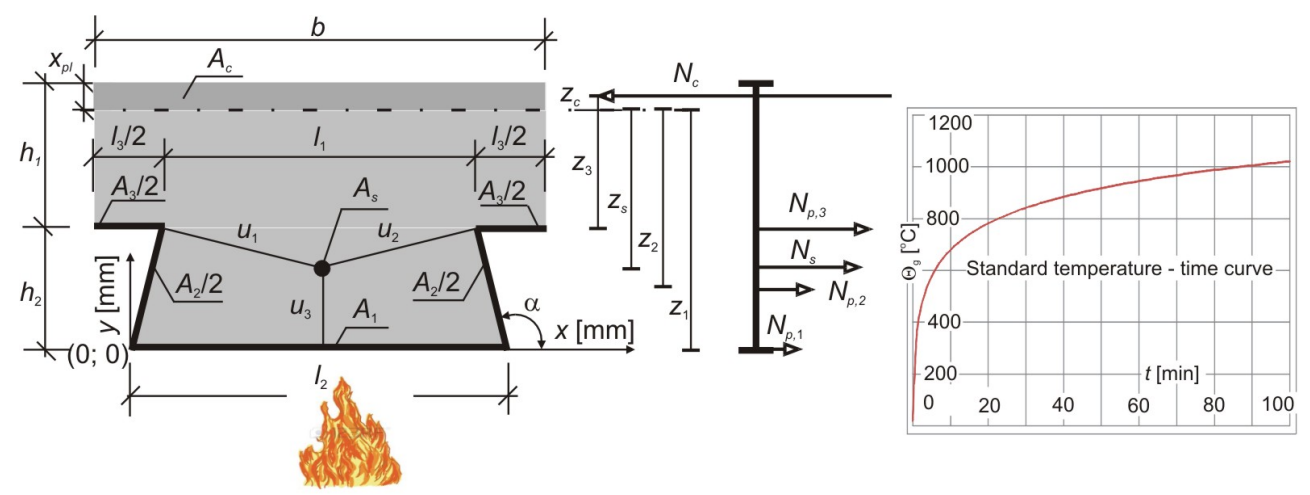

Fig.2. The cross-section of the analyzed rib of slab Cofrastra 40

The rib geometry parameters and their values indicated in Fig. 2 corresponding to the slab assumed in [1] are the following:

$-l_{1}=103,5[\mathrm{~mm}]-$ the distance between the upper corners of the profiled steel sheet,

$-l_{2}=124[\mathrm{~mm}]-$ the width of the lower flange of the steel sheet,

$-l_{3}=46,5[\mathrm{~mm}]-$ the width of the upper flange of the steel sheet,

$-b=l_{1}+l_{3}=150[\mathrm{~mm}]$ - the width of the slab rib,

$-h_{1}=50[\mathrm{~mm}]-$ the thickness of the concrete slab above the steel sheet,

- $h_{2}=40[\mathrm{~mm}]-$ the height of the steel sheet, 
- $A$ - concrete volume of the rib per meter of the rib length $\left[\mathrm{mm}^{3} / \mathrm{m}\right]$, calculated according to the formula (1)

$$
A=h_{2} \cdot\left(\frac{l_{1}+l_{2}}{2}\right)=4550\left[\mathrm{~mm}^{3} / \mathrm{m}\right]
$$

- $L_{r}$ - exposed surface determined following the formula (2)

$$
L_{r}=l_{2}+2 \cdot \sqrt{h_{2}^{2}+\left(\frac{l_{1}-l_{2}}{2}\right)^{2}}=206\left[\mathrm{~mm}^{2} / \mathrm{m}\right]
$$

- $u_{1}=u_{2}=54,4[\mathrm{~mm}]-$ the shortest distance of the centre of the reinforcement bar to any point of the webs of the steel sheet,

$-u_{3}=23[\mathrm{~mm}]-$ the distance of the reinforcement bar to the lower flange of the steel sheet, $-\alpha=104^{\circ}-$ angle of the web.

Additional geometry parameters of the rib, calculated basing on the above-mentioned, are as follows:

- the rib geometry factor: $A / L_{r}=22[\mathrm{~mm}]$,

- the configuration factor of the upper flange $\Phi$, determined as follows:

$$
\Phi=\left(\sqrt{h_{2}^{2}+\left(l_{3}+\frac{l_{1}-l_{2}}{2}\right)^{2}}-\sqrt{h_{2}^{2}+\left(\frac{l_{1}-l_{2}}{2}\right)^{2}}\right) / l_{3}=0,27[-]
$$

- and the indication of the position of the reinforcement bar in the rib, which is given by:

$$
z=\left(1 / \sqrt{u_{1}}+1 / \sqrt{u_{2}}+1 / \sqrt{u_{3}}\right)^{-1}=2,08\left[\mathrm{~mm}^{-0,5}\right]
$$

\section{The design moment resistance of the rib}

The design moment resistance $M_{f i, t, R d}$ was determined according to the simple calculation model, defined in [7]. The rules of this model apply to calculating the standard fire resistance of both simple supported and continuous slabs with profiled steel sheets and reinforcement when heated from below according to the standard temperature-time curve, defined in [6]. It was assumed that the investigated steel sheet is directly heated and is not protected by any insulation, see Fig.2. The design bending resistance is determined by plastic theory according to the formula (5):

$$
M_{f i, t, R d}=\sum_{i=1}^{n=3} A_{i} z_{i} k_{y, \Theta, i}\left(\frac{f_{y, a}}{\gamma_{M, f i}}\right)+A_{s} z_{s} k_{y, \Theta, s}\left(\frac{f_{y, s}}{\gamma_{M, f i}}\right)+\alpha_{s l a b} A_{c} z_{c} k_{c, \Theta}\left(\frac{f_{c}}{\gamma_{M, f i, c}}\right)
$$

where : $A_{i}, i=1,2,3$ - is the elemental steel area, where $A_{1}$ is the area of the lower flange, $A_{2}$ is the area of the upper flange and $A_{3}$ is the area of the web of the steel sheet, $A_{s}-$ is the area of the reinforcing bar, $A_{c}=x_{p l} \cdot b-$ is the area of compression concrete, where $x_{p l}$ is the range of the concrete compression area and $b$ is the width of the analyzed slab rib, 
$\alpha_{s l a b}=0,85-$ is the coefficient taking into account the assumption of the rectangular stress block when designing slabs,

$f_{y, a}$ - is the nominal yield strength for the elemental steel area $A_{i}$,

$f_{y, s}$ - is the nominal yield strength for the area of reinforcing bar,

$f_{c}-$ is the design strength for concrete area,

$\gamma_{M, f i}$ - is the partial factor for relevant material property, for the fire situation. For thermal properties of steel and concrete, the recommended value is $\gamma_{M, f i}=1,0$, see [6]

$z_{i}, z_{s}, z_{c}$ - is the distance from the plastic neutral axis to the centroid of the elemental area $A_{i}, A_{s}, A_{c}$, respectively, see Fig.2.

The plastic neutral axis of composite slab is determined basing on the condition for equilibrium of the resultant forces: the compressive one in the concrete $N_{c}=\alpha_{s l a b} \cdot A_{c} \cdot f_{c, \Theta}$, and the tensile force in particular elements of the steel sheet: $N_{p, 1}=A_{1} \cdot f_{y, a, \Theta, 1}, N_{p, 2}=$ $A_{2} \cdot f_{y, a, \Theta, 2}, N_{p, 3}=A_{3} \cdot f_{y, a, \Theta, 3}$, respectively and in the reinforcement bar $N_{s}=A_{\mathrm{s}} \cdot f_{y, s, \Theta}$. The balance of forces of the cross-section and the geometry parameters of the assumed model are indicated in Fig. 2. The range of the concrete compression area $x_{p l}$ was calculated from the formula (6).

$$
x_{p l}=\frac{\sum_{i=1}^{n=3} A_{i} k_{y, \Theta, i}\left(\frac{f_{y, a}}{\gamma_{M, f i}}\right)+A_{s} k_{y, \Theta, s}\left(\frac{f_{y, s}}{\gamma_{M, f i}}\right)}{\alpha_{s l a b} \cdot b \cdot k_{c, \Theta} \cdot\left(\frac{f_{c}}{\gamma_{M, f i, c}}\right)}
$$

The parameters $k_{y, \Theta, i}, k_{y, \Theta, s}, k_{c, \Theta}$, in the formulae (5) and (6) are reduction coefficients allowing calculation of the values reduced due to the increased temperature: the strength yield of the $i$-th element of the steel sheet $f_{y, a, \theta, i}=k_{y, \theta, i} \cdot f_{y, a}$, yield strength of the reinforcement bar $f_{y, s, \theta}=k_{y, \theta, s} \cdot f_{y, s}$, and the compression strength of the concrete $f_{c, \theta}=k_{c, \theta} \cdot f_{c}$. The values of the coefficients are determined according to item 3.2 in [7] respectively to the determined temperature of particular elements of the analyzed rib cross-section. The temperature of each element is calculated according to the attachment D to the standard [7], respectively to the assumed fire resistance class $R 60$ following the dependences below:

- the temperatures $\theta_{a}$ of the lower flange, web, or upper flange:

$$
\theta_{a}=b_{0}+b_{1} \cdot \frac{1}{l_{3}}+b_{2} \cdot \frac{A}{L_{r}}+b_{3} \cdot \Phi+b_{4} \cdot \Phi^{2},
$$

- the temperature $\theta_{s}$ of the reinforcement bars in the rib:

$$
\theta_{s}=c_{0}+c_{1} \cdot \frac{u_{3}}{h_{2}}+c_{2} \cdot z+c_{3} \cdot \frac{A}{L_{r}}+c_{4} \cdot \alpha+c_{5} \cdot \frac{1}{l_{3}},
$$

- the temperature $\theta_{c}$ of the concrete was referred to the temperature of the area distant from the upper slab by $h_{1} / 2$. The temperature of this surface was determined according to the temperature distribution in a solid slab of effective thickness $h_{\text {eff }}$ composed of normal weight concrete and not insulated, referred to in attachment D to the standard [7]. The effective slab thickness was calculated according to the formula: 


$$
h_{\text {eff }}=h_{1}+0,5 h_{2} \cdot\left(\frac{l_{1}+l_{2}}{l_{1}+l_{3}}\right)
$$

In the formulae (6-9) the parameters: $b_{0}, b_{1}, b_{2}, b_{3}, b_{4}$ are coefficients for determination of the temperatures of the parts of the steel sheet, the values of which are shown in Table D. 2 of the [7]; $c_{0}, c_{1}, c_{2}, c_{3}, c_{4}, c_{5}$ are coefficients for the determination of the temperatures of the reinforcement bars in the rib, according to Table D.3 of the [7], the importance of the other parameters is as indicated above.

The bending resistance $M_{f i, t, R d}$ defined according to the above procedure and the formula (5), depends on the following set of basic variables: $\mathbf{X}=\left\{l_{1}, l_{2}, l_{3}, h_{2} t, \alpha, \phi,(y, z), h_{1}, f_{y, a}\right.$, $\left.f_{y, s}, f_{c}\right\}$, where $(x, y)$ are the coordinates of the location of the reinforcement bar in the rib, referred to the coordinate system shown in Fig. 2 . The bending resistance $M_{f i, t, R d}$ of the slab rib was calculated with the defined in [1] values of basic variables $\mathbf{X}$, representing the state of reference. It was assumed, that the resulting value of the bending resistance $M_{f, t, R d}=M_{0}$ $=1,42 \mathrm{kNm}$ is the reference value in the sensitivity analysis conducted hereinafter. The values of basic variables and the values of parameters necessary for determining the bending resistance $M_{0}$, calculated on the basis of hose basic variables, are presented in Table 1 - 3 .

Table 1. Values of basic variables according to [1].

\begin{tabular}{|c|c|c|c|c|c|c|c|c|c|c|c|}
\hline $\begin{array}{c}\boldsymbol{l}_{\mathbf{1}} \\
{[\mathrm{mm}]}\end{array}$ & $\begin{array}{c}\boldsymbol{l}_{\mathbf{2}} \\
{[\mathrm{mm}]}\end{array}$ & $\begin{array}{c}\boldsymbol{l}_{\mathbf{3}} \\
{[\mathrm{mm}]}\end{array}$ & $\begin{array}{c}\boldsymbol{h}_{\mathbf{2}} \\
{[\mathrm{mm}]}\end{array}$ & $\begin{array}{c}\boldsymbol{t} \\
{[\mathrm{mm}]}\end{array}$ & $\begin{array}{c}\boldsymbol{\alpha} \\
{\left[{ }^{\circ}\right]}\end{array}$ & $\begin{array}{c}\boldsymbol{\phi} \\
{[\mathrm{mm}]}\end{array}$ & $\begin{array}{c}\boldsymbol{( x , y )} \\
{[\mathrm{mm}]}\end{array}$ & $\begin{array}{c}\boldsymbol{h}_{\mathbf{1}} \\
{[\mathrm{mm}]}\end{array}$ & $\begin{array}{c}\boldsymbol{f}_{\boldsymbol{y}, \boldsymbol{a}} \\
{\left[\mathrm{N} / \mathrm{mm}^{2}\right]}\end{array}$ & $\begin{array}{c}\boldsymbol{f}_{\boldsymbol{y}, \boldsymbol{s}} \\
{\left[\mathrm{N} / \mathrm{mm}^{2}\right]}\end{array}$ & $\begin{array}{c}\boldsymbol{f}_{\boldsymbol{c}} \\
{\left[\mathrm{N} / \mathrm{mm}^{2}\right]}\end{array}$ \\
\hline 103,5 & 124 & 46,5 & 40 & 0,75 & 104 & 6 & $\begin{array}{c}(62, \\
23)\end{array}$ & 50 & 350 & 500 & 25 \\
\hline
\end{tabular}

Table 2. Coefficients for determination of the temperatures of elements of the rib. Calculated temperatures $\theta_{a, i}, \theta_{s}, \theta_{c}$ and reduction factors $k_{y, \theta, i}, k_{y, \theta, s}, k_{c}, \theta$.

\begin{tabular}{|c|c|c|c|c|c|c|c|c|c|c|}
\hline \multicolumn{2}{|c|}{$\begin{array}{c}\text { Part of the steel } \\
\text { sheet }\end{array}$} & $\begin{array}{c}\boldsymbol{b}_{0} \\
{\left[{ }^{\circ} \mathrm{C}\right]}\end{array}$ & $\begin{array}{c}\boldsymbol{b} \mathbf{1} \\
{\left[{ }^{\circ} \mathrm{C} \cdot \mathrm{mm}\right]}\end{array}$ & $\begin{array}{c}\boldsymbol{b}_{\mathbf{2}} \\
{\left[{ }^{\circ} \mathrm{C} \cdot \mathrm{mm}\right.} \\
]\end{array}$ & $\begin{array}{c}\boldsymbol{b}_{3} \\
{\left[{ }^{\circ} \mathrm{C}\right]}\end{array}$ & $b_{4}\left[{ }^{\circ} \mathrm{C}\right]$ & $A / L_{r}$ & $\Phi$ & $\begin{array}{c}\theta_{a} \\
{\left[{ }^{\circ} \mathrm{C}\right]}\end{array}$ & $\boldsymbol{k}_{y, \theta}$ \\
\hline \multicolumn{2}{|c|}{ Lower flange } & 1 & -1197 & $-2,32$ & 86,4 & 50,7 & 2,02 & 0,27 & 386,5 & 0,067 \\
\hline \multicolumn{2}{|l|}{ Web } & 661 & -83 & $-2,96$ & 537,7 & 9 & & & 698,4 &, 234 \\
\hline \multicolumn{2}{|c|}{ Upper flange } & 340 & -3269 & $-2,62$ & 1148,4 & $-679,8$ & & & 474,8 & 0,836 \\
\hline \multirow[t]{2}{*}{$\begin{array}{c}\text { Reinforcement } \\
\text { bar }\end{array}$} & $\begin{array}{c}c_{0} \\
{\left[{ }^{\circ} \mathrm{C}\right]}\end{array}$ & $\begin{array}{c}c_{1} \\
{\left[{ }^{\circ} \mathrm{C}\right]}\end{array}$ & $\begin{array}{c}\boldsymbol{c}_{\mathbf{2}} \\
{\left[{ }^{\circ} \mathrm{C} \cdot \mathrm{mm}^{0,5}\right.} \\
]\end{array}$ & $\begin{array}{c}c_{3} \\
{\left[{ }^{\circ} \mathrm{C} \cdot \mathrm{mm}\right.} \\
]\end{array}$ & $\begin{array}{c}c_{4} \\
{\left[{ }^{\circ} \mathrm{C} /{ }^{\circ}\right]}\end{array}$ & $\begin{array}{c}c_{5} \\
{\left[{ }^{\circ} \mathrm{C} \cdot \mathrm{mm}\right.} \\
]\end{array}$ & $\begin{array}{c}\boldsymbol{u}_{3} \\
{[\mathrm{~mm}]}\end{array}$ & {$\left[\begin{array}{c}\boldsymbol{z} \\
{\left[\mathrm{mm}^{0,5}\right]}\end{array}\right.$} & $\begin{array}{c}\theta_{s} \\
{\left[{ }^{\circ} \mathrm{C}\right]}\end{array}$ & $\boldsymbol{k}_{\boldsymbol{y}, \theta, \mathrm{s}}$ \\
\hline & 1191 & -250 & -240 & $-5,01$ & 1,0 & -925 & 23 & 2,08 & 495,5 & 0,682 \\
\hline \multirow{2}{*}{\multicolumn{2}{|c|}{ Concrete }} & $\begin{array}{c}\boldsymbol{h}_{\text {eff }} \\
{[\mathrm{mm}]}\end{array}$ & $\begin{array}{c}\boldsymbol{x}^{\left(^{*}\right)} \\
{[\mathrm{mm}]}\end{array}$ & $\begin{array}{c}\theta_{c} \\
{\left[{ }^{\circ} \mathrm{C}\right]}\end{array}$ & $\boldsymbol{k}_{\boldsymbol{c}, \theta}$ & & \multirow{2}{*}{$\mathrm{h}_{1} / 2 \uparrow$} & \multirow{2}{*}{\multicolumn{3}{|c|}{$\begin{array}{l}\text { Temperature distribution } \\
\text { in a concrete slab }\end{array}$}} \\
\hline & & 80,3 & 55,3 & 198,3 & 0,95 & & & & & \\
\hline
\end{tabular}

${ }^{(*)}$ the distance $\boldsymbol{x}$ is measured as in Figure in Table 2.

Table 3. Values of parameters for determination of the reference value of $M_{f i, t, R d}=M_{0}$.

\begin{tabular}{|c|c|c|c|c|c|c|c|c|c|c|c|}
\hline $\begin{array}{c}\boldsymbol{x}_{\boldsymbol{p}} \\
{[\mathrm{mm}]}\end{array}$ & $\begin{array}{c}\boldsymbol{z}_{\mathbf{1}} \\
{[\mathrm{mm}]}\end{array}$ & $\begin{array}{c}\boldsymbol{z}_{\mathbf{2}} \\
{[\mathrm{mm}]}\end{array}$ & $\begin{array}{c}\boldsymbol{z}_{\mathbf{3}} \\
{[\mathrm{mm}]}\end{array}$ & $\begin{array}{c}\boldsymbol{z}_{\boldsymbol{s}} \\
{[\mathrm{mm}]}\end{array}$ & $\begin{array}{c}\boldsymbol{z}_{\boldsymbol{c}} \\
{[\mathrm{mm}]}\end{array}$ & $\begin{array}{c}\boldsymbol{A}_{\mathbf{1}} \\
{\left[\mathrm{mm}^{2}\right]}\end{array}$ & $\begin{array}{c}\boldsymbol{A}_{\mathbf{2}} \\
{\left[\mathrm{mm}^{2}\right]}\end{array}$ & $\begin{array}{c}\boldsymbol{A}_{\mathbf{3}} \\
{\left[\mathrm{mm}^{2}\right]}\end{array}$ & $\begin{array}{c}\boldsymbol{A}_{\boldsymbol{s}} \\
{\left[\mathrm{mm}^{2}\right]}\end{array}$ & $\begin{array}{c}\boldsymbol{A}_{\boldsymbol{c}} \\
{\left[\mathrm{mm}^{2}\right]}\end{array}$ & $\begin{array}{c}\boldsymbol{M}_{\boldsymbol{f}, \boldsymbol{t}, \boldsymbol{R} \boldsymbol{R}} \\
{[\mathrm{kNm}]}\end{array}$ \\
\hline 8,94 & 81,06 & 28,94 & 41,06 & 58,06 & 4,47 & 93 & 61,9 & 34,9 & 28,3 & 1340,5 & 1,42 \\
\hline
\end{tabular}




\section{Sensitivity analysis}

A subset $\mathbf{X}_{\mathbf{1}}=\left\{(y, z), h_{1}, f_{y, a}, f_{y, s}, f_{c}\right\}$ was selected from the set of basic variables $\mathbf{X}=\left\{l_{1}, l_{2}\right.$, $\left.l_{3}, h_{2} t, \alpha, \phi,(y, z), h_{1}, f_{y, a}, f_{y, s}, f_{c}\right\}$. The elements of the subset determine the range of the sensitivity analysis. Five analyses that referred to resepctive elements of the set $\mathbf{X}_{\mathbf{1}}$ were carried out. In every analysis made, one of the elements of the set $\mathbf{X}_{\mathbf{1}}$ was treated as a variable, whereas the other elements of the set were treated as constant with the values as shown in Table 1 . For a selected variable, a range of its variability was determined as well as a set of its values comprised by that range. Furthermore, for every value of that set a corresponding value of the design moment resistance $M_{f i, t, R d}$ was calculated. The resulting set of values $M_{f i, t, R d}$ was then subject to the analysis which meant to determine the range of variability and to compare the extreme values with the reference value $M_{0}$.

\section{1 $M_{f i, t, R d}$ value with a varied location $(x, y)$ of the reinforcement bar}

It was assumed, that the location of the reinforcement bar in the slab rib varies and the values of the other basic variables were as presented in Table 1. The bar location is identified by the coordinates $(x, y)$ of the centre of its cross-section in the assumed coordinate system presented in Fig. 2. The area where the bar can be located is limited with the straight lines: $x_{\min }=\left(l_{2}-l_{1}+\phi\right) / 2=13,25 \mathrm{~mm}, x_{\max }=\left(l_{2}+l_{1}-\phi\right) / 2=110,75 \mathrm{~mm} ; y_{\min }=$ $\phi / 2=3 \mathrm{~mm}, y_{\max }=h_{2}+3 \mathrm{~mm}=43 \mathrm{~mm}$ forming a rectangular with the sides of $\Delta x \times \Delta y=$ $97,5 \mathrm{~mm} \times 40 \mathrm{~mm}$. The value of $M_{f i, t, R d}$ was calculated for all the combinations $\left(x_{i}, y_{i}\right)$ of the sets: $\mathbf{x}=\left\{x_{\min }: 9,75 \mathrm{~mm}: x_{\max }\right\}, \mathbf{y}=\left\{y_{\min }: 4 \mathrm{~mm}: y_{\max }\right\}$. The calculation results obtained for the fixed values of $x$ and the varied values of $y$ are presented as graphs in Fig. 3a) and b) respectively.
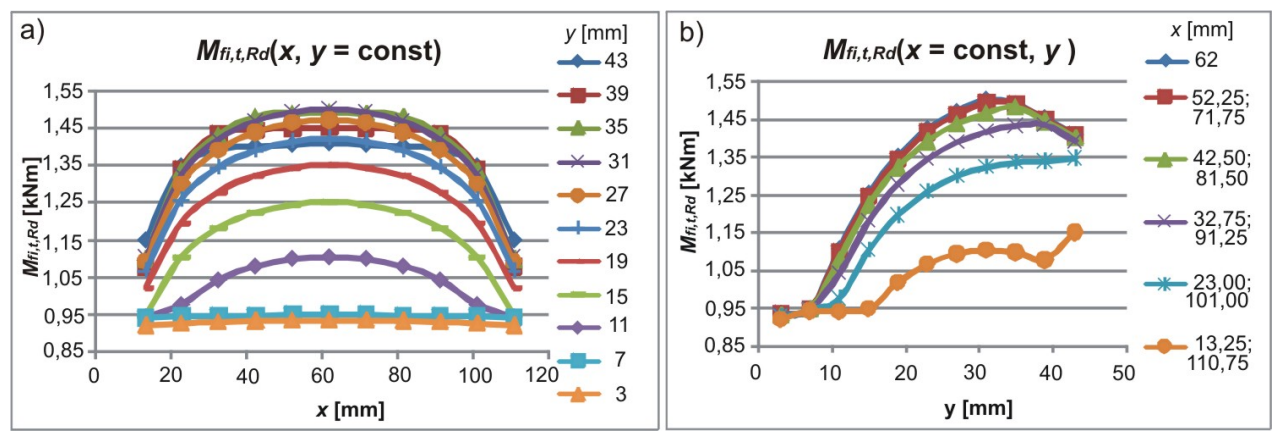

Fig. 3. Graphs $M_{f i, t, R d}(x, y)$ for the fixed values of: a) y = const.; b) $x=$ const.

The extreme values obtained are the following: $M_{f i, t, R d, \text { min }}=0,92 \mathrm{kNm}=0,65 M_{0}$ and $M_{f i, t, R d, \max }=1,50 \mathrm{kNm}=1,05 M_{0}$. The rib has the highest bending resistance when the reinforcement bar has the locations of $(x=62 \mathrm{~mm}, y=31 \mathrm{~mm})$ and the lowest one with $(x=$ $13,25 \mathrm{~mm}, y=3 \mathrm{~mm})$ and $(x=110,75 \mathrm{~mm}, y=3 \mathrm{~mm})$. The analysis of the graphs in Fig. 3 leads to the conclusion, that a change of the bar location within the area $\left(x=x_{0} \pm 0,2 \Delta x, y\right.$ $\left.=\left(y_{0}+0,2 \Delta y ; y_{0}+0,5 \Delta y\right)\right)$, where the coordinates $\left(x_{0}=62 \mathrm{~mm}, y_{0}=23 \mathrm{~mm}\right)$ are the coordinates of the reference state, slightly changes the bending resistance $M_{f i, t, R d}$, namely $M_{f i, t, R d}, \in\left(1,05 M_{0}=1,50 \mathrm{kNm} ; 0,98 M_{0}=1,40 \mathrm{kNm}\right)$. 


\section{2 $M_{f i, t, R d}$ value with a varied thickness of the concrete slab $h_{1}$}

The analysis assumed variability of the thickness $h_{1}$ of the concrete slab above the steel sheet. It was accepted, that $h_{1}$ changes from $40 \mathrm{~mm}$ to $70 \mathrm{~mm}$ along with the increment of $\Delta h_{1}=0,1 h_{1,0}=5 \mathrm{~mm}$, where $h_{1,0}=50 \mathrm{~mm}$ is the reference thickness, to which the bending resistance $M_{0}=1,42 \mathrm{kNm}$ corresponds. Fig. $4 \mathrm{a}$ ) shows the calculated values of $M_{f i, t, R d}$ and their corresponding values of the variable $h_{1}$.
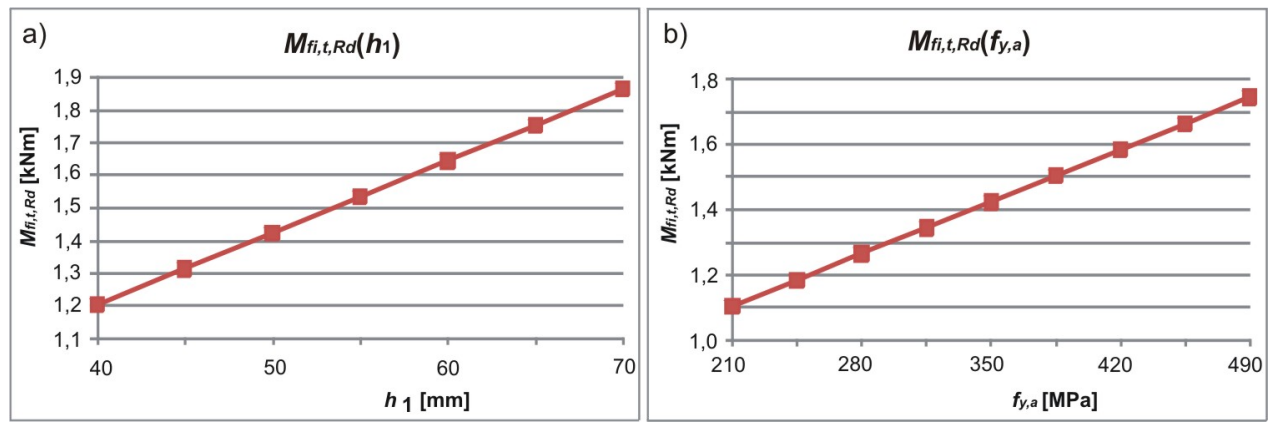

Fig. 4. Dependence: a) $M_{f i, t, R d}\left(h_{1}\right)$; b) $M_{f i, t, R d}\left(f_{y, a}\right)$.

The created graph illustrates a linear dependence of $M_{f, t, R d}\left(h_{1}\right)$. The values of $h_{1}$ from the assumed variability range have their corresponding values of $M_{f i, t, R d}$ from the range $\left[M_{f i, t, R d, \text { min }}=1,2 \mathrm{kNm}=0,85 M_{0} ; M_{f i, t, R d, \text { max }}=1,86 \mathrm{kNm}=1,31 M_{0}\right]$. An increase of $h_{1}$ by $0,1 h_{1,0}$ leads to an increase of the rib bending resistance by $0,077 M_{0}$.

\section{$5.3 M_{f i, t, R d}$ value with a varied yield strength $f_{y, a}$}

$f_{y, a}$ - the nominal yield strength for the elemental steel area $A_{i}$ of the sheet was taken as a variable. Bending resistance calculations $M_{f i, t, R d}\left(f_{y, a}\right)$ were made for the value of $f_{y, a}$ from the range of $\left[0,6 f_{y, a, 0}=210 ; 1,4 f_{y, a, 0}=490 \mathrm{MPa}\right]$ accepted with the increment of $\Delta f_{y, a}=0,1 f_{y, a, 0}$, where $f_{y, a, 0}=350 \mathrm{MPa}$ is the reference value. Basing on the obtained results, a dependence graph was made $M_{f i, t, R d}\left(f_{y, a}\right)$, which is shown in Fig. 4b). As in 5.2, the dependence is linear. In this case, $10 \%$ increase of fy,a results in $5,6 \%$ increase in the bending resistance, from $M_{f, t, R d, \min }=1,1 \mathrm{kNm}=0,77 M_{0}$ to $M_{f i, t, R d, \max }=1,74 \mathrm{kNm}=1,23 M_{0}$.

\section{$5.4 M_{f i, t, R d}$ value with a varied yield strength $f_{y, s}$}

It was found, that the values of the nominal yield strength $f_{y, s}$ for the reinforcing bar vary. The bending resistance $M_{f i, t, R d}$ was calculated respectively for each value of $f_{y, s}$ from the range $\left[0,6 f_{y, s, 0}=300 ; 1,4 f_{y, s, 0}=700 \mathrm{MPa}\right]$, determined so that $f_{y, s,(i+1)}=f_{y, s, i}+\Delta f_{y, s}$ where $f_{y, s, 0}$ $=500 \mathrm{MPa}$ is the reference value and $\Delta f_{y, s}=0,1 f_{y, s, 0}=50 \mathrm{MPa}$. The dependence graph $M_{f i, t, R d}\left(f_{y, s}\right)$, made on the basis of the calculation results obtained is presented in Fig. 5a). It shows, that the dependence is linear. The extreme values are: $M_{f, t, R d, \min }=1,18 \mathrm{kNm}=$ $0,83 M_{0}, M_{f, t, R d, \max }=1,66 \mathrm{kNm}=1,17 M_{0}$. The increase in yield strength $f_{y, s}$ by $\Delta f_{y, s}=0,1 f_{y, s, 0}$ $=50 \mathrm{MPa}$ is reflected by an increment of the bending resistance by $\Delta M_{f i, t, R d}=0,06 \mathrm{kNm}=$ $0,042 M_{0}$. 

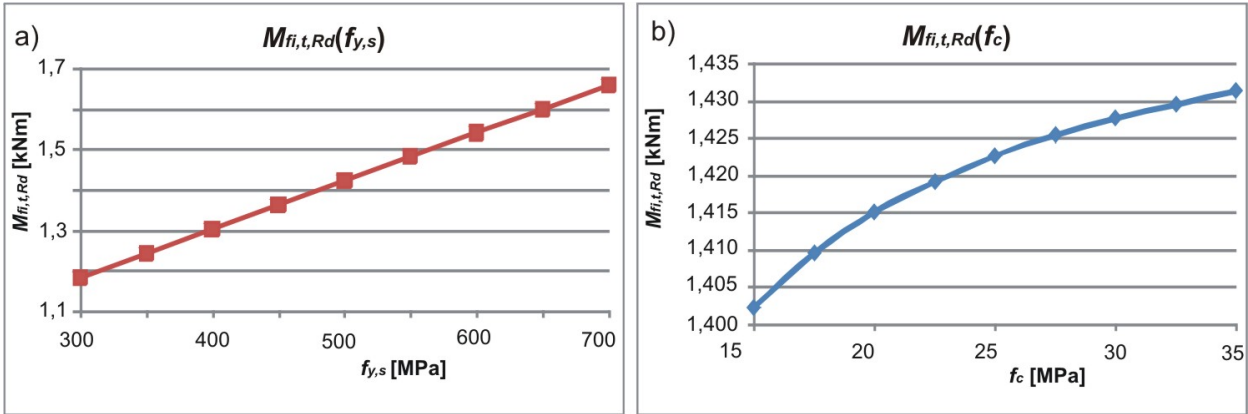

Fig. 5. The dependence: a) $M_{f i, t, R d}\left(f_{y, s}\right)$; b) $M_{f i, t, R d}\left(f_{c}\right)$

\section{5 $M_{f i, t, R d}$ value with a varied design strength for concrete $f_{c}$}

The set of values of the design strength for concrete $f_{c}$ from $\left[0,6 f_{c, 0}=15 ; 1,4 f_{c, 0}=35 \mathrm{MPa}\right]$ was used for the calculations, assuming a constant difference between consecutive values of $\Delta f_{c, s}=0,1 f_{c, 0}=2,50 \mathrm{MPa}$, where $f_{c, 0}=25,0 \mathrm{MPa}$ is the reference value. The extremes of the calculated set of values $M_{f i, t, R d}\left(f_{c}\right)$ are: $M_{f i, t, R d, \text { min }}=1,4 \mathrm{kNm}=0,986 M_{0}, M_{f i, t, R d, \max }=1,43$ $\mathrm{kNm}=1,007 \mathrm{M} 0$. The dependence $M_{f i, t, R d}\left(f_{c}\right)$ is nonlinear, which is illustrated by the graph presented in Fig. 5b). The biggest increment of the bending resistance is here $\Delta M f i, t, R d=$ $0,008 \mathrm{kNm}=0,0056 M_{0}$ corresponding to the value of strength for concrete from $f_{c}=15$ $\mathrm{MPa}$ to $f_{c}=17,5 \mathrm{MPa}$. The average increment of the bending resistance $M_{f i, t, R d}\left(f_{c}\right)$ for the whole variability range $f_{c}$ is $\Delta M_{f i, t, R d}=0,0025 M_{0}$.

\section{Conclusions}

The results, being the basis for the sensitivity analysis are presented in Table 4 as well as in graphs presented in Fig. 6. Table 4. illustrates the accepted ranges of variability of the nominal values $x \mathrm{i} / x i_{0}$ for particular basic variables from the set $\mathbf{X} 1=\left\{x 1=x\left(y_{0}\right) ; x 2=y\left(x_{0}\right)\right.$ $\left.\left.x 3=h 1 ; x 4=f_{y, a} ; x 5=f_{y, s}, x 6=f_{c} ;\right)\right\}$, their corresponding nominal max and min values of bending resistance $M_{f i, t, R d, \max } / M_{0}, M_{f i, t, R d, \min } / M_{0}$, respectively and nominal values of the bending resistance increases $\Delta M_{f i, t, R d} / M_{0}$ corresponding to the nominal increments of variables $\Delta x i / x i_{0}$, where $x i_{0}$ are the reference values accepted in accordance with Table 1.

Table 4. Results of sensitivity analysis.

\begin{tabular}{|c|c|c|c|c|}
\hline \multicolumn{2}{|r|}{ Basic variable $x i$} & $M_{\min } / M_{0}$ & $M_{\max } / M$ & $\Delta M(\Delta x i) / M 0$ \\
\hline \multirow{3}{*}{ 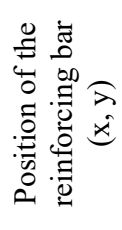 } & $\begin{array}{l}y \in\left[0,1 y_{0} ; 0,3 y_{0}\right] \\
x \in\left[0,2 x_{0} ; 1,8 x_{0}\right]\end{array}$ & 0,65 & 0,67 & $2,1 \cdot 10^{-4}$ \\
\hline & $\begin{array}{c}y \in\left[0,5 y_{0} ; 0,8 y_{0}\right] \\
x \in\left[0,2 x_{0} ; 0,7 x_{0}\right] \cup\left[1,3 x_{0} ; 1,8 x_{0}\right]\end{array}$ & 0,66 & 0,93 & avr: 0,056 \\
\hline & $\begin{array}{c}y \in\left[y_{0} ; 1,9 y_{0}\right] \\
x \in\left[0,7 x_{0} ; 1,3 x_{0}\right]\end{array}$ & 0,9 & 1,05 & avr: 0,007 \\
\hline \multicolumn{2}{|r|}{$h_{1} \in\left[0,8 h_{1,0} ; 1,4 h_{1,0}\right]$} & 0,85 & 1,31 & 0,077 \\
\hline \multicolumn{2}{|r|}{$f_{y, a} \in\left[0,6 f_{y, a, 0} ; 1,4 f_{y, a, 0}\right]$} & 0,77 & 1,23 & 0,056 \\
\hline \multicolumn{2}{|r|}{$f_{y, s} \in\left[0,6 f_{y, s, 0} ; 1,4 f_{y, s, 0}\right]$} & 0,83 & 1,17 & 0,042 \\
\hline \multicolumn{2}{|r|}{$f_{c} \in\left[0,6 f_{c, 0} ; 1,4 f_{c, 0}\right]$} & 0,986 & 1,007 & avr:0,0025 \\
\hline
\end{tabular}

In Table: $y_{0}=23 \mathrm{~mm} ; x_{0}=62 \mathrm{~mm} ; h_{1,0}=50 \mathrm{~mm} ; f_{y, a, 0}=350 \mathrm{MPa} ; f_{y, s, 0}=500 \mathrm{MPa} ; f_{c, 0}=25 \mathrm{MPa}$ reference values of basic variables; $M_{0}=M_{f i, t, R d, 0}=1,42 \mathrm{kNm} ; M_{\max }=M_{f i, t, R d, \max } ; M_{\text {min }}=M_{f i, t, R d, \min }$; $\Delta M(\Delta x i)=\Delta M_{f i, t, R d}(\Delta x i)-$ increment of the design moment resistance $M_{f i, t, R d}$ corresponding to an increment of basic variable $x i$; avr - average value. 
The graphs in Fig. 6 present the dependence of the nominal value $M_{f i, t, R d} / M_{0}$ on the nominal value of the variable $x i / x i_{0}$ for which the bending resistance was calculated. The graphs corresponding to the varied position of the reinforcement bar $(x, y)$, refer only to two representative cases, namely:1) the position $y=y_{0}=23 \mathrm{~mm}$ is fixed and the coordinate $x$ varies; 2) the position $x=x_{0}=62 \mathrm{~mm}$ is fixed and $y$ varies.

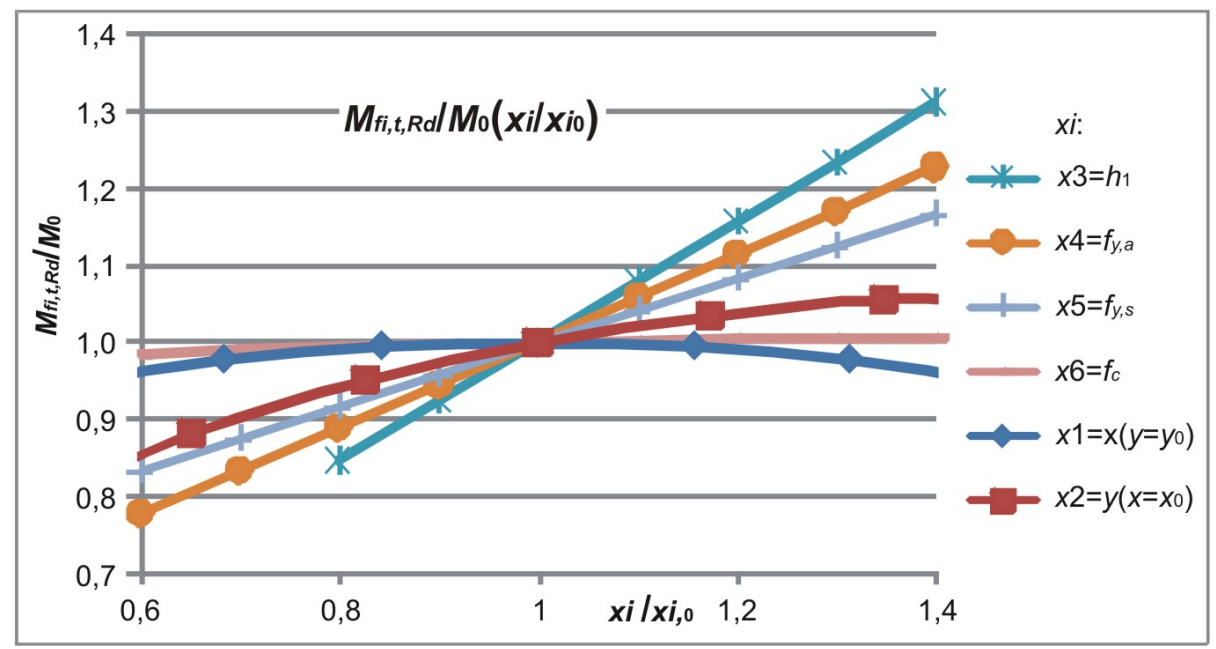

Fig. 6. Dependence between relative increase of the moment resistance $M_{f i, t, R d}$ and relative increase of the value of basic variable $x i$.

The sensitivity analysis made leads to the following conclusions:

- A varied sensitivity of the calculated bending resistance $M_{f i, t, R d}$ to a change of the value of particular basic variables from the set $\mathbf{X}_{\mathbf{1}}$ is found;

- The biggest changes of $M_{f i, t, R d}$ value come along with changes in thickness of the slab above the steel sheet $h_{1}$, where the variability range $M_{f i, t, R d} \in\left[0,85 M_{0} ; 1,31 M_{0}\right]$ corresponds to the variability range of $h_{1} \in\left[0,8 h_{1,0} ; 1,4 h_{1,0}\right]$.

- The lowest sensitivity can be observed with changes of the value of concrete compression strength $f_{c}$. In this case, the values $f_{c}$ from the range $\left[0,6 f_{c, 0} ; 1,4 f_{c, 0}\right]$ correspond to the values $M_{f i, t, R d}$ from the range $\left[0,986 M_{0} ; 1,007 M_{0}\right]$.

- The bending resistance $M_{f i, t, R d}$ shows a similar sensitivity to a change of the value of yield strength of steel sheet $f_{y, a}$ and the yield strength of the reinforcement bar $f_{y, s}$. The variability ranges $f_{y, a} \in\left[0,6 f_{y, a, 0} ; 1,4 f_{y, a, 0}\right]$ and $f_{y, s} \in\left[0,6 f_{y, s, 0} ; 1,4 f_{y, s, 0}\right]$ correspond to the values $M_{f, t, R d}$ from the ranges $\left[0,77 M_{0} ; 1,23 M_{0}\right]$ and $\left[0,83 M_{0} ; 1,17 M_{0}\right]$, respectively.

- Three areas of the location of the reinforcement bar can be distinguished, for which sensitivity of bending resistance $M_{f i, t, R d}$ to a change of location within the area of each of them is different. These areas are: 1) $y \in\left[0,1 y_{0} ; 0,3 y_{0}\right] ; x \in\left[0,2 x_{0} ; 1,8 x_{0}\right]$ its corresponding range of variability of bending resistance is : $M_{f i, t, R d} \in\left[0,65 M_{0} ; 0,67 M_{0}\right]$. In this location of the reinforcement bar, the rib has the lowest bending resistance and is not subject to a vivid change. 2) $y \in\left[0,5 y_{0} ; 0,8 y_{0}\right] ; x \in\left[0,2 x_{0} ; 0,7 x_{0}\right] \cup\left[1,3 x_{0} ; 1,8 x_{0}\right]$ within this area the resistance presents a significant sensitivity to a change of the location of the reinforcement bar, the obtained values fit into the range of $\left.M_{f i, t, R d} \in\left[0,66 M_{0} ; 0,93 M_{0}\right] .3\right) y \in\left[y_{0} ; 1,9 y_{0}\right] ; x$ $\in\left[0,7 x_{0} ; 1,3 x_{0}\right]$ it is the area that refers to the highest bending resistance of the rib and a change of the bar location within this area slightly affects a change of the bending resistance value $M_{f i, t, R d} \in\left[0,98 M_{0} ; 1,06 M_{0}\right]$. 


\section{References}

1. E. Grochowska, J. Kaliszuk, Renowacje drewnianych stropów z wykorzystaniem zespolonych plyt stropowych (to be published)

2. A. Matysiak, E. Grochowska, K. Hamudi, Ekspertyza techniczna dotyczaca stanu technicznego budynku znajdującego się przy ul. dr Pieniężnego 27 w Zielonej Górze, Opracowanie Zespołu Rzeczoznawców przy PZITB oddział Zielona Góra, (Zielona Góra, 2014)

3. Rozporządzenie Ministra Infrastruktury z dnia 12 kwietnia 2002 r. w sprawie warunków technicznych, jakim powinny odpowiadać budynki i ich usytuowanie (Dz.U. $2002 \mathrm{nr} 75$, poz. 690)

4. Praca zbiorowa pod kierunkiem M. Gieżejowskiego i J. Ziółko Budownictwo ogólne tom 5. Stalowe konstrukcje budynków projektowanie wedtug eurokodów z przykładami obliczeń, rozdział 10., M. Maślak, Odporność ogniowa. Nośność konstrukcji w warunkach pożaru. (Arkady, Warszawa, 2010)

5. Cofrastra 40. Tablice obciążeń. ArcelorMittal, WWW.constructalia.com, 29.11.2017 r.

6. EN 1991-1-2 Eurocode 1: Actions on structures - Part 1-2 :General action - Actions on structures exposed to fire

7. EN 1994-1-2 Eurocode 4 : Design of composite steel and concrete structures - Part 12 : General rules - Structural fire design 